\title{
SELEÇÃO DE MATERIAIS PARA LANÇAS DE INJEÇÃO DE CARVÃO PULVERIZADO (PCI)*
}

Claudemir Ribeiro ${ }^{1}$ Juliana Satie Watai

\section{Resumo}

A lança de injeção de carvão pulverizado (PCI) é um método consolidado na indústria siderúrgica, que possibilita a redução do consumo de carvão vegetal ou de coque de carvão metalúrgico enfornado, além do ganho de produtividade. A seleção de materiais adequados para a lança de injeção é de suma importância para agregar ainda mais valor ao método. A finalidade deste trabalho é nortear a seleção das ligas aplicadas em alta temperatura, visando o melhor custo benefício, por meio das análises da resistência à corrosão, fluência e estabilidade estrutural. Foram realizados testes em uma usina siderúrgica chinesa com as ligas Sandvik 253 MA $^{\text {TM }}$ (UNS S30815) e UNS S32109. A experiência demonstrou como as siderúrgicas podem obter ganhos com a seleção adequada da liga. O custo-benefício do 253MA que é ligado ao Cério, Silício e Nitrogênio, mostra-se como uma ótima alternativa para o processo de injeção de carvão, devido a sua alta resistência à oxidação, à fluência e à erosão. Outras ligas como UNS S30403, UNS S31009 e UNS N08810, que são muito utilizadas em alta temperatura nas indústrias em geral, também foram analisadas como comparativo.

Palavras-chave: Seleção de materiais; Siderúrgica; Lanças de injeção; Alto-forno.

\section{MATERIALS SELECTION FOR PULVERIZED COAL INJECTION (PCI)}

\begin{abstract}
The pulverized coal injection ( $\mathrm{PCl}$ ) is an established method in steel industry that enables the reduction of consumption of charcoal and metallurgical coke in the process and increases the productivity. The materials selection for coal injection lance is very important to add value for the method. The aim of this work is guiding the materials selection for grades used in high temperature process, aiming to cost efficiency, going through corrosion resistance, creep and structural stability analysis. Tests were carried out in a chinese steel industry with Sandvik 253 MA $^{\text {TM }}$ (UNS S30815) and UNS S32109. The experience revealed how steel industries might gain with a suitable materials selection. The cost efficiency of 253MA, that is alloyed with Cerium, Silicon and Nitrogen, showed as a good alternative to pulverized coal injection process, due to high resistance to oxidation, creep and erosion. Other alloys like UNS S30403, UNS S31009 and UNS N08810 that are commonly used in high temperature application were also analyzed as comparative.

Keywords: Materials selection; Steel industry; Pulverized coal injection; Blast furnace.

1 Graduado em Engenharia de Produção, Engenheiro de Aplicações, Engenharia de Aplicações, Sandvik Materials Technology do Brasil, São Paulo, Brasil.

2 Graduanda em Engenharia de Materiais, Engenharia de Aplicações, Engenharia de Aplicações, Sandvik Materials Technology do Brasil, São Paulo, Brasil.
\end{abstract}




\section{INTRODUÇÃO}

Corrosão em alta temperatura é um desafio generalizado em diversas indústrias, tais como: geração de energia (combustível nuclear e fóssil); aeroespacial e gás turbina; tratamento térmico, mineral e processamento metalúrgico; refino e petroquímica; automotivo; papel e celulose e incineração de resíduos. Embora a maioria das reações de corrosão em alta temperatura ocorra acima de $500^{\circ} \mathrm{C}\left(930^{\circ} \mathrm{F}\right)$, corrosões também podem ser vistas em temperatura inferior $500^{\circ} \mathrm{C}\left(930^{\circ} \mathrm{F}\right)$ [1].

A injeção de carvão pulverizado $(\mathrm{PCl})$ é uma operação utilizada na redução de minério, onde as lanças injetam o carvão no alto-forno pelas ventaneiras com ar quente de temperatura de aproximadamente entre $800^{\circ} \mathrm{C}$ e $1300^{\circ} \mathrm{C}$ [2]. Os benefícios econômicos proporcionados pelo uso de injeção de carvão são a redução do custo de produção de gusa, pois os finos têm menor preço no mercado, aumento de produtividade e redução de emissão de $\mathrm{CO}_{2}$. O aspecto econômico foi o principal motivo para o desenvolvimento dos sistemas de injeção, visto que o custo do petróleo fez com que as usinas repensassem seus métodos de produção [3].

Tanto a temperatura quanto a velocidade de fluxo do carvão variam de equipamento para equipamento e influenciam na estabilidade e produtividade na redução do minério, bem como a composição do carvão. Dessa forma, uma análise mais abrangente na seleção do material se faz necessária, pois a lança de injeção deve ter as características adequadas para suportar a exposição ao ar quente, além de resistir à carbonetação, que pode ocorrer devido ao acúmulo do carvão na superfície do metal. Sabendo que a velocidade de injeção de carvão é relativamente alta, a resistência à erosão torna-se essencial para a seleção dos tubos utilizados como lanças [2].

Este trabalho aborda uma experiência com uma siderúrgica chinesa comparando os tubos em Sandvik 253 MATM(UNS S30815) e UNS S32109 (TP 321H). Foi evidenciado que a seleção de materiais de forma adequada pode gerar ganhos para a siderúrgica, bem como a diminuição do ciclo de custos envolvidos no processo de troca da lança.

\subsection{Seleção de Materiais para lanças}

$\mathrm{Na}$ seleção de ligas usadas em alta temperatura, devem-se avaliar algumas características importantes além da resistência à corrosão, tais como: estabilidade estrutural e propriedades mecânicas (resistência à tração e fluência) [1].

Em muitas indústrias e processos são utilizadas diferentes ligas para aplicação em alta temperatura. Sabe-se que a seleção de materiais é complexa, devido a muitas variáveis envolvidas e é muito difícil simular testes laboratoriais com as condições de processo. No entanto, testes realizados em laboratório podem fornecer uma boa orientação para seleção da liga [1].

Para uma seleção adequada e mais próxima da realidade da aplicação, todas as informações das condições operacionais devem ser disponibilizadas e analisadas de acordo com os próximos tópicos.

\subsubsection{Condições de processo}

Sabe-se que os materiais utilizados para suportar alta temperatura podem estar expostos em diferentes atmosferas, onde os materiais estão sujeitos a diversos mecanismos de corrosão. Portanto, deve-se conhecer a composição química dos meios presentes na parte interna e externa dos tubos. Determinados parâmetros 
como, temperatura do processo, temperatura de pele e sua variação ao longo da extensão do tubo e do tempo de exposição, pressão de trabalho e velocidade do fluxo de partículas, também devem ser considerados.

No caso de gases de combustão é importante analisar se os gases possuem oxigênio em excesso, ou sua ausência, e se na composição dos gases há impurezas como: enxofre, vanádio, cloretos, potássio [2].

A carbonetação pode ocorrer quando o material entra em contato com gases quentes com carbono de alta atividade química, como por exemplo, o dos hidrocarbonetos. O grau da carbonetação depende da composição da liga e das porcentagens de carbono e oxigênio do gás carbonetante [2].

Por sua vez, a nitretação ocorre em ambientes ricos em Nitrogênio. Assim, o desempenho do material está totalmente relacionado à sua composição química [2].

\subsubsection{Materiais em uso ou testados previamente}

Por meio da análise do material utilizado previamente, consegue-se informações importantes para a seleção do material a ser testado, como o tipo de aço e sua vida útil e propriedades que o levaram a ser escolhido. Além dessas características mencionadas, mecanismos de falha encontrados também devem ser analisados, como: tipo de corrosão, fragilização, fluência, falha na soldagem e baixa resistência mecânica. Esse histórico auxilia na seleção de um material mais adequado para a aplicação [2].

\subsubsection{Fabricação}

Nas operações de dobramento ou soldagem dos tubos, alguns cuidados devem ser tomados para que não ocorram perdas nas propriedades mecânicas e na resistência à corrosão dos aços, devido à possibilidade de ocorrência de mudanças estruturais durante as operações.

Dessa forma, as informações técnicas de como os tubos serão curvados, a frio ou a quente, o raio de curvamento imposto e os parâmetros de soldagem possibilitam a análise e decisão no que se refere a tratamento térmico dos tubos após curvamento e soldagem [2].

\subsubsection{Limpeza do sistema}

É importante conhecer qual método foi utilizado (mecânico ou químico) e a frequência da limpeza, em razão de formação de condensados corrosivos que podem gerar corrosão intergranular ou corrosão sob tensão [2].

\subsection{Propriedades dos materiais}

Para a aplicação de lanças de injeção de carvão pulverizado, a seleção de materiais será determinada principalmente por fatores como resistência à corrosão, estabilidade estrutural e resistência mecânica (fluência). Neste trabalho serão analisados, de forma mais detalhada, os materiais Sandvik 253 MA $^{\text {TM }}$ (UNS S30815) e UNS S32109 (TP 321H), por terem sido acompanhados em testes numa siderúrgica chinesa. A tabela 1 apresenta a composição química dos materiais mencionados e outros que também podem ser aplicados em alta temperatura. 
Tabela 1. Composição química de alguns materiais aplicados em altas temperaturas e que podem ser utilizados em lanças de injeção de carvão pulverizado $[4,5,6,7,8,9]$

\begin{tabular}{|c|c|c|c|c|c|c|c|c|c|c|}
\hline & UNS & C & $S i$ & Mn & $\mathbf{P}$ & S & $\mathrm{Cr}$ & $\mathrm{Ni}$ & $\mathbf{N}$ & Outros \\
\hline 253MA & S30815 & 0,08 & 1,6 & $\leq 0,8$ & $\leq 0,040$ & $\leq 0,030$ & 21 & 11 & 0,17 & $\mathrm{Ce}^{*}=0,05$ \\
\hline 353MA & S35315 & 0,07 & 1,6 & 1,5 & $\leq 0,040$ & $\leq 0,015$ & 25 & 35 & 0,16 & $\mathrm{Ce}^{*}=0,05$ \\
\hline $321 / 321 \mathrm{H}$ & S32100/S32109 & 0,05 & 0,5 & 1,3 & $\leq 0,030$ & $\leq 0,030$ & 17,5 & 10,5 & - & $>5 \times C$ \\
\hline $304 / 304 \mathrm{~L}$ & S30400/S30403 & $\leq 0,030$ & 0,5 & 1,3 & $\leq 0,030$ & $\leq 0,015$ & 18,5 & 10 & - & - \\
\hline $310 \mathrm{~S} / 310 \mathrm{H}$ & S31008/S31009 & 0,06 & $\leq 0,75$ & 1,5 & $\leq 0,030$ & $\leq 0,015$ & 24,5 & 21 & - & - \\
\hline Alloy $800 \mathrm{H}$ & N08811/N08810 & 0,07 & 0,6 & 0,6 & $\leq 0,015$ & $\leq 0,010$ & 20,5 & 30,5 & - & $\begin{aligned} \mathrm{Ti} & =0,5 \\
\mathrm{Al} & =0,5 \\
\mathrm{Fe} & =\text { bal. }\end{aligned}$ \\
\hline
\end{tabular}

${ }^{*} \mathrm{~A}$ quantidade de Cério deve ser adicionada aos demais metais terras raras, pois a adição é feita na forma de uma mistura de metais onde a \% de cério está próxima de $50 \%$.

O UNS S30815 é um aço inoxidável austenítico ligado ao Silício, Nitrogênio e metais terras raras (MTR), especificamente o Cério. Este material apresenta elevada resistência à corrosão em alta temperatura principalmente pelo efeito da camada de óxido fina, densa e rica em Cromo. Abaixo dessa camada, o Silício é oxidado internamente, formando um padrão dendrítico de ramos finos perto da interface óxido/metal e mais escassamente espalhado em direção a matriz do aço, delineando os contornos de grão. A camada de óxido torna-se mais aderente, elástica e impermeável, criando uma espécie de barreira na difusão [2].

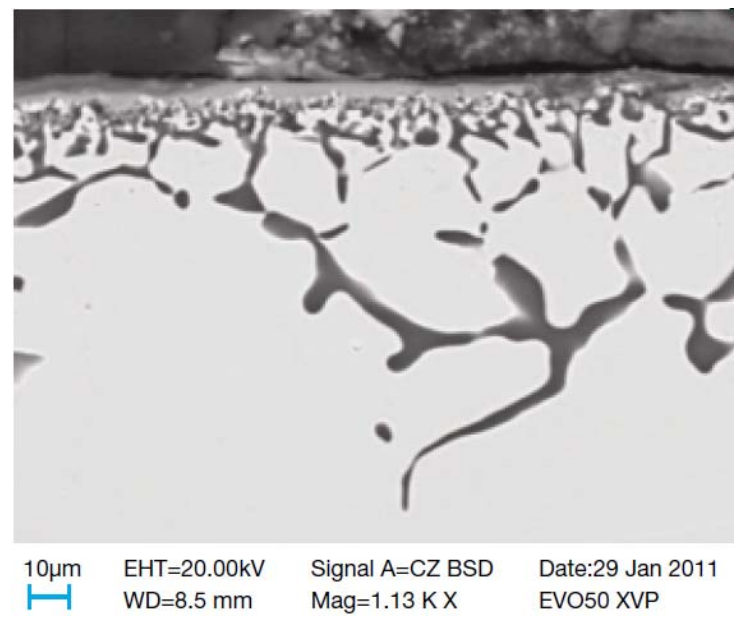

Figura 1. Imagem da interface oxido/metal, em material exposto descontinuamente por $1000 \mathrm{~h} \mathrm{a}$ $1000^{\circ} \mathrm{C}$, obtida por MEV (Microscopia Eletrônica de Varredura) [2].

Junto com o Silício, o Cério melhora a resistência à corrosão. A sua presença promove oxidação seletiva de Cromo que minimiza a taxa de oxidação e aumenta a adesão de óxido ao substrato. Uma explicação para este fenômeno é a reação de partículas de elementos que atuam como pontos de nucleação, diminuindo as distâncias entre os núcleos de óxido e o tempo para formar a camada de proteção em todo o metal [2].

Por sua vez, o aço UNS S32109 (TP321H) é um aço inoxidável austenítico, estabilizado com Titânio/Nióbio, que é recomendado em meios com corrosão úmida, mas também possui boa resistência mecânica em altas temperaturas. A estabilização com Titânio ou Nióbio proporciona ao UNS S32109 uma melhora na resistência à corrosão intergranular, sendo superior ao aço UNS S30403 [6, 7]. Porém, o uso desses elementos para estabilização não assegura uma completa imunidade contra a sensitização e ataque intergranular, principalmente quando é exposto por longos períodos a temperaturas entre 425 e $815^{\circ} \mathrm{C}\left(800\right.$ à $\left.1500^{\circ} \mathrm{F}\right)$ [10]. 
A resistência em meios com gás de sulfeto de hidrogênio e corrosão intergranular, aliada à resistência a altas temperaturas faz do UNS S32109 (TP321H) um material recomendado para aplicações em fornos, trocadores de calor e tubulações nas indústrias química e petroquímica [6].

A tabela 2 apresenta propriedades mecânicas, estruturais e térmicas dos materiais que podem ser utilizados em altas temperaturas.

Tabela 2. Propriedades mecânicas, estruturais e térmicas dos materiais aplicados em altas temperaturas [2]

\begin{tabular}{|c|c|c|c|c|c|c|}
\hline Propriedades & UNS S30815 & UNS S35315 & UNS S32109 & UNS S30403 & UNS S31009 & UNS N08810 \\
\hline Resistência à Tração (MPa) & $650-850$ & $\geq 650$ & $515-690$ & $515-680$ & $530-750$ & 480 \\
\hline $\begin{array}{c}\text { Resistência ao escoamento } \\
0,2 \%(\mathrm{MPa}) \\
20^{\circ} \mathrm{C}\end{array}$ & $\geq 310$ & $\geq 300$ & $\geq 210$ & $\geq 210$ & $\geq 240$ & 175 \\
\hline $\begin{array}{c}\text { Resistência ao escoamento } \\
0,2 \%(\mathrm{MPa}) \\
600^{\circ} \mathrm{C}\end{array}$ & $\geq 140$ & $\geq 138$ & $\geq 120$ & $\geq 100$ ou 95 & $\geq 121$ ou 119 & 95 \\
\hline Alongamento (\%) & $\geq 40$ & $\geq 40$ & $\geq 35$ & $\geq 45$ & $\geq 35$ & $\geq 30$ \\
\hline Dureza (Vickers) & $\approx 190$ & $\approx 160$ & $\leq 185$ & $\leq 185$ & $\leq 185$ & $\leq 185$ \\
\hline $\begin{array}{c}\text { Resistência à Corrosão } \\
\text { em alta temperatura } \\
\text { ao ar }\end{array}$ & até $1150^{\circ} \mathrm{C}$ & até $1150^{\circ} \mathrm{C}$ & at $850^{\circ} \mathrm{C}$ & at $850^{\circ} \mathrm{C}$ & até $1150^{\circ} \mathrm{C}$ & até $1100^{\circ} \mathrm{C}$ \\
\hline $\begin{array}{c}\text { Resistência à Corrosão } \\
\text { em alta temperatura } \\
\text { em atmosfera sulfurosa oxidante }\end{array}$ & até $1100^{\circ} \mathrm{C}$ & até $1100^{\circ} \mathrm{C}$ & até $750^{\circ} \mathrm{C}$ & até $750^{\circ} \mathrm{C}$ & até $1050^{\circ} \mathrm{C}$ & até $900^{\circ} \mathrm{C}$ \\
\hline $\begin{array}{c}\text { Resistência à Corrosão } \\
\text { em alta temperatura } \\
\text { em atmosfera sulfurosa redutora }\end{array}$ & $650^{\circ} \mathrm{C}-950^{\circ} \mathrm{C}$ & $650^{\circ} \mathrm{C}-950^{\circ} \mathrm{C}$ & até $600^{\circ} \mathrm{C}$ & até $600^{\circ} \mathrm{C}$ & até $950^{\circ} \mathrm{C}$ & até $750^{\circ} \mathrm{C}$ \\
\hline $\begin{array}{c}\text { Resistência à Corrosão } \\
\text { em alta temperatura } \\
\text { em atmosfera sulfurosa } \\
\text { alternada entre oxidante e } \\
\text { redutora }\end{array}$ & $950^{\circ} \mathrm{C}-1000^{\circ} \mathrm{C}$ & $950^{\circ} \mathrm{C}-1000^{\circ} \mathrm{C}$ & - & - & $900^{\circ} \mathrm{C}-950^{\circ} \mathrm{C}$ & $700^{\circ} \mathrm{C}-750^{\circ} \mathrm{C}$ \\
\hline $\begin{array}{c}\text { Estabilidade } \\
\text { Estrutural }\end{array}$ & $\begin{array}{c}\text { Boa, pequena } \\
\text { quantidade de } \\
\text { fase sigma }\end{array}$ & $\begin{array}{l}\text { Boa, pequena } \\
\text { quantidade de } \\
\text { fase sigma }\end{array}$ & $\begin{array}{c}\text { Formação de fase } \\
\text { sigma }\end{array}$ & $\begin{array}{c}\text { Formação de fase } \\
\text { sigma }\end{array}$ & $\begin{array}{c}\text { Formação de fase } \\
\text { sigma }\end{array}$ & $\begin{array}{c}\text { Boa, pequena } \\
\text { quantidade de } \\
\text { fase sigma }\end{array}$ \\
\hline Soldabilidade & Boa & Boa & Aceitável & Aceitável & Aceitável & Aceitável \\
\hline Dobramento & Bom & Bom & Bom & Bom & Bom & Não tão bom \\
\hline
\end{tabular}

O aço UNS S30815 tem ótima resistência à oxidação ao ar tanto em condições de operação isotérmica como cíclicas, sendo especialmente melhor em condições de operação cíclica. A razão é que a boa adesão, impermeabilidade e a grande elasticidade da camada de óxido rica em sílica, originam uma alta resistência à escamação, mesmo durante rápidas flutuações de temperatura [2].

Como se pôde observar na tabela 2, o material UNS S30815 apresenta dureza (190 HV) superior aos outros aços austeníticos e à liga de Níquel. Essa característica se mostra interessante para os tubos que são aplicados como lanças, devido à ocorrência de erosão provocada pela velocidade do carvão, que pode se agravar pelo material estar submetido à alta temperatura [2]. Portanto, o UNS S30815 comparado com os outros materiais, apresenta-se como o mais adequado na aplicação de lanças de injeção por possuir dureza superior, entre outras características.

Com relação à estabilidade estrutural, praticamente todos os aços desenvolvidos para trabalhar em meios corrosivos em alta temperatura podem sofrer fragilização devido à formação de fases secundárias, sendo o tipo mais comum a fase sigma, que é geralmente formada após longo período de trabalho na faixa de 600 a $850{ }^{\circ} \mathrm{C}$. A quantidade de fase sigma formada está relacionada com a composição química do 
material. Materiais ricos em Cromo e outros elementos ferritizantes são mais propensos a formar fase sigma, enquanto que elementos austenitizantes como Níquel e Nitrogênio dificultam e retardam a sua formação [2].

O UNS S30815 contém menos Cromo e é ligado ao Nitrogênio, que é altamente austenitizante e um ótimo inibidor de fase sigma. Por conta dessas características, esta liga é menos susceptível a esta fragilização que os outros aços austeníticos como, por exemplo, UNS S30403, UNS S31009, UNS S32109, quando expostos por períodos prolongados em alta temperatura.

Por sua vez, a resistência à fluência também é importante para selecionar o material mais adequado para a aplicação. A tensão de projeto para um material especifica a carga a qual este material pode ser submetido em alta temperatura sem falhar ou ser deformado significativamente durante o seu trabalho. Dessa forma, a resistência à fluência do material deve ser conhecida para saber se ele é capaz de suportar as condições na aplicação [2].

Desde a temperatura ambiente até certa faixa de temperatura $\left(550-600^{\circ} \mathrm{C}\right)$ as tensões de projeto são baseadas no limite de escoamento a deformação de $0,2 \%$ do material. Para temperaturas superiores, a resistência à fluência passa a determinar os valores de tensão de projeto [2].

Como regra, a resistência à fluência é expressa como resistência à ruptura por fluência após 10.000 ou 100.000 h. Para componentes que são mais sensíveis à deformação, a resistência à deformação por fluência, ou seja, a tensão que resulta em uma deformação de $1 \%$ após 10.000 ou 100.000 horas deve ser usada como base para os cálculos de projeto. A resistência mecânica em curto prazo do UNS S30815 para temperaturas até $550^{\circ} \mathrm{C}$ é maior que as demais ligas [2].

A figura 2 apresenta a resistência à fluência para os materiais já citados.

\section{Resistência à fluência}

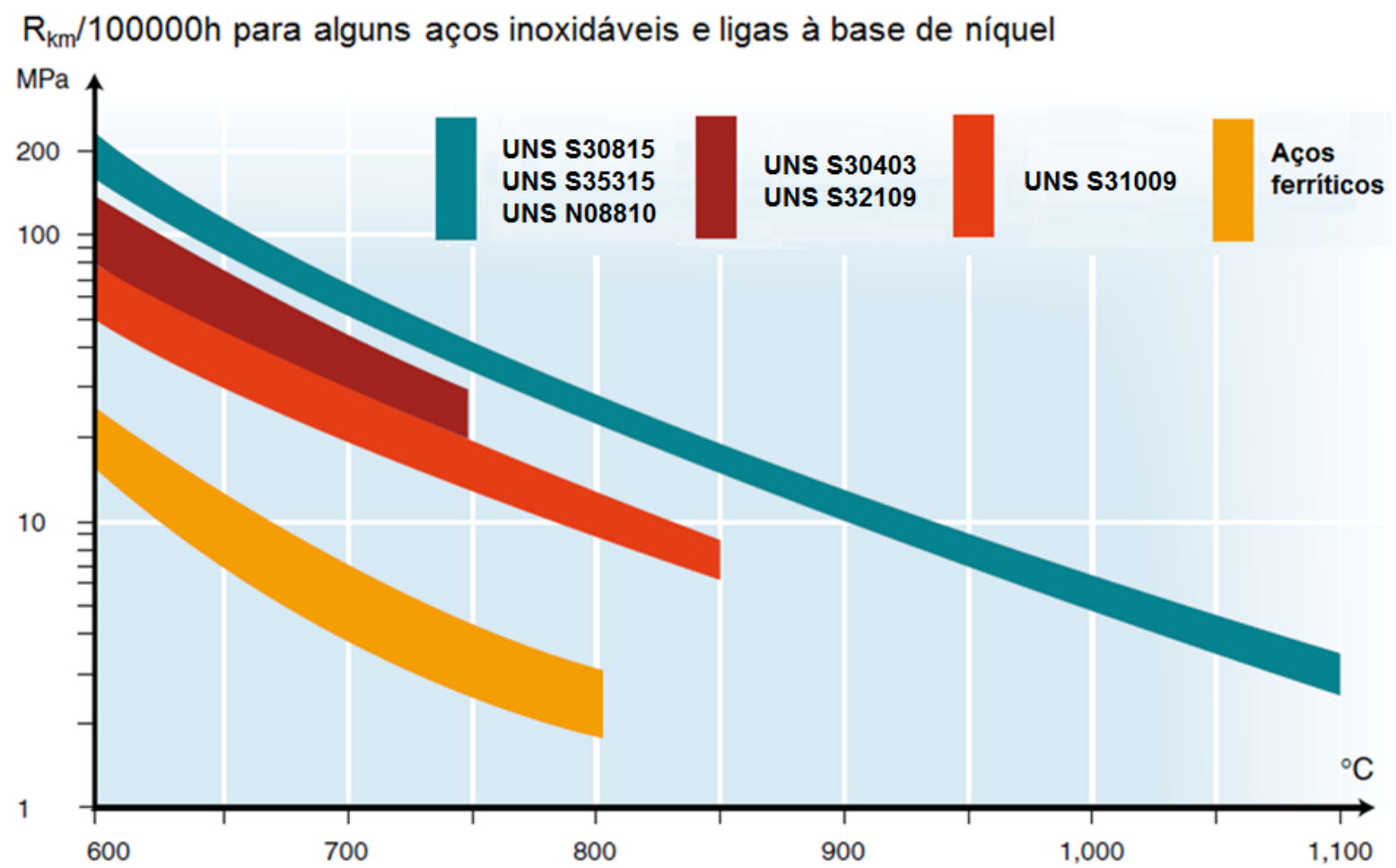

Figura 2. Resistência à ruptura por fluência para alguns aços inoxidáveis e ligas a base de níquel. 
Serão abordados de forma superficial alguns tipos de corrosão em alta temperatura, em que o UNS S30815 também se apresenta como uma ótima alternativa. Por sua composição química conter baixo teor de níquel, ele possui uma melhor resistência ao ataque de atmosferas sulfurosas oxidantes, e também levemente redutoras, do que as ligas austeníticas com teor de níquel mais alto [2].

Entretanto, se a atmosfera sulfurosa for acentuadamente redutora, ou seja, se o oxigênio para a combustão for à quantidade bem menor que a estequiometricamente necessária para a queima completa do combustível contendo enxofre, o UNS S30815 não é recomendado. Portanto, a composição química da combustão é extremamente relevante na seleção de materiais em alta temperatura [2].

A boa resistência a carbonetação do UNS S30815 é devido ao alto teor de Cromo e adição de Silício. Já os metais terras raras que facilitam a formação do óxido de sílica, faz com que a camada fique aderente, elástica e impermeável, dificultando a penetração do carbono no metal [2].

Todavia, em atmosferas alternativamente oxidantes e carbonetantes e em escorias carbonetantes, o UNS S30815 é ligeiramente mais propenso a sofrer carbonetação que aços com teor mais elevado de cromo e/ou níquel [2].

O UNS S30815 pode ser usado em atmosferas que contenham nitrogênio desde que o gás contenha oxigênio suficiente para formar a camada protetora de óxidos já descrita [2].

\section{ESTUDO DE CASO}

Atualmente a China se destaca entre os países com maior produção de aço, possuindo um mercado forte e agressivo no cenário mundial. Uma siderúrgica chinesa, líder em produção de aço, buscou o suporte técnico na Sandvik para a seleção dos materiais para lanças de injeção de carvão pulverizado (PCI). O objetivo era estender o tempo de vida útil das lanças, que é considerado um dos componentes mais importantes do alto-forno. Foram analisados os custos envolvidos na troca de lanças, pois a lança utilizada, UNS S32109 (TP321H), apresentava uma vida útil curta $e$, assim, decidiu-se testar outra liga com propriedades mais adequadas ao processo. Após conhecer as condições dos dez altos-fornos da siderúrgica, a Sandvik recomendou o material Sandvik 253 MA $^{\text {TM }}$ (UNS S30815). Para os testes, foram selecionados dois fornos dos dez altos-fornos em operação. As condições de operação, dimensões das lanças, material utilizado e o tempo de vida útil estão apresentados na tabela 3.

As lanças foram instaladas no forno $n^{\circ} 1$ no dia 19 de abril de 2014 e no dia seguinte no forno $n^{\circ} 9$. Durante os testes, a Sandvik realizou acompanhamento técnico, mêsa-mês "in loco" verificando o desempenho do material.

Tabela 3.Condições de operação, dimensões das lanças, material utilizado e tempo de vida útil utilizados na siderúrgica chinesa

\begin{tabular}{|c|c|c|c|c|c|c|c|c|}
\hline $\mathbf{N}^{0}$ & Volume & $\begin{array}{c}\text { Início } \\
\text { Produção }\end{array}$ & $\begin{array}{c}\text { Capacidade } \\
\left(10^{6} \text { tano }\right)\end{array}$ & $\begin{array}{c}\text { Quantidade } \\
\text { tubos } \\
\text { (peças) }\end{array}$ & $\begin{array}{c}\text { Temperatura } \\
\text { do ar } \\
\left({ }^{\circ} \mathrm{C}\right)\end{array}$ & $\begin{array}{c}\text { Dimensão } \\
\text { do tubo } \\
(\mathrm{mm})\end{array}$ & Material & $\begin{array}{l}\text { Vida útil } \\
\text { (meses) }\end{array}$ \\
\hline 1 & 450 & Janeiro 2008 & 60 & 14 & $1100-1200$ & OD $25 \times 2 \times 1550$ & \multirow[b]{2}{*}{ UNS S32109 } & \multirow[b]{2}{*}{$1-2$} \\
\hline 9 & 1080 & Agosto 2011 & 120 & 20 & $1200-1250$ & $\begin{array}{c}\text { OD } 27 \times 4 \times 1750 \\
4,5 \mathrm{~kg} / \text { peça }\end{array}$ & & \\
\hline
\end{tabular}




\section{RESULTADOS E DISCUSSÃO}

A siderúrgica chinesa obteve um aumento da vida útil das lanças de injeção substituindo o material UNS S32109 pelo material Sandvik 253 MA $^{\mathrm{TM}}$ (UNS S30815), que se mostrou uma liga com ótimo desempenho na aplicação. As propriedades abordadas ao longo deste trabalho foram o diferencial para suportar as condições a qual o material foi exposto, contribuindo para o aumento da vida útil de um a dois meses do material UNS S32109 (TP321H) para 10 meses com UNS S30815. O suporte técnico provido ao longo dos meses foi importante para certificar o desempenho do material e verificar possíveis variações das condições operacionais do alto-forno que poderiam ser adicionados ao relatório. Entretanto não houve qualquer instabilidade relevante que poderia ser acrescentada. As fotos apresentadas na figura 3 foram tiradas durante o teste para a comprovação e elaboração deste trabalho.

Após 1 mês

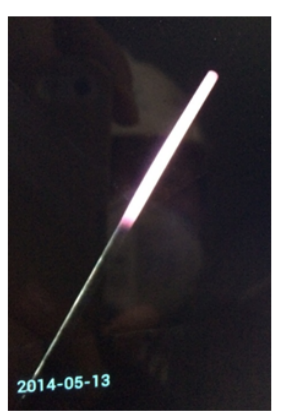

Após 2 meses

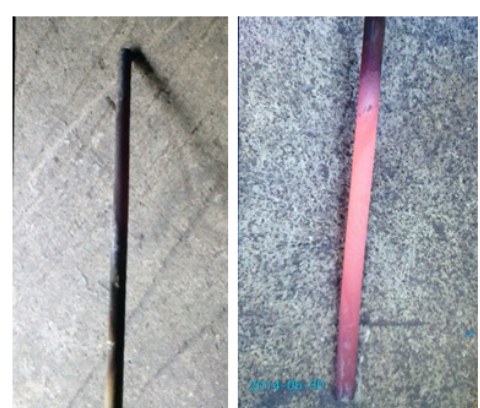

Após 4 meses

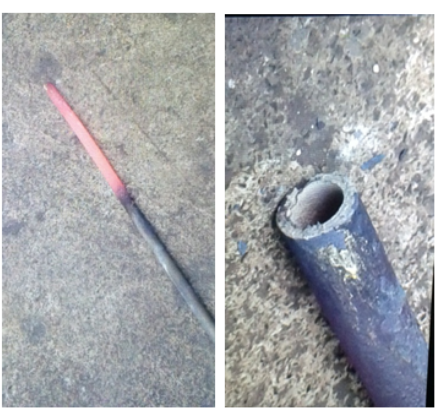

Após 5 meses
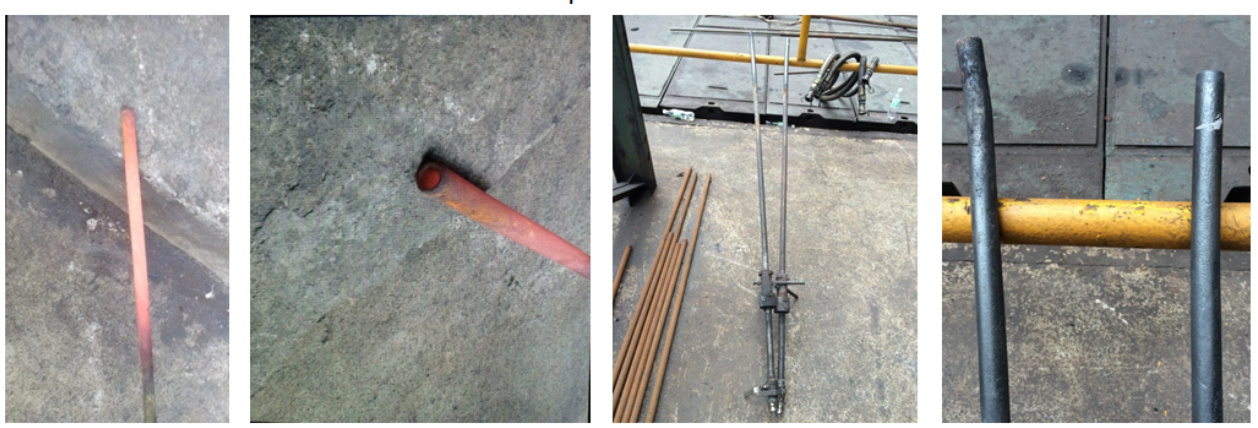

Figura 3. Fotos do material ao longo do teste na siderúrgica chinesa.

Após a realização dos testes, foram equacionados todos os custos envolvidos para os dois materiais. O custo-benefício do material UNS S30815 é significativamente maior do que UNS S32109, mostrando uma redução dos custos implicados na troca de lança ao longo dos dez meses. Com a substituição do UNS S30815 para outros oito altos-fornos o resultado se torna ainda mais atrativo para a planta siderúrgica. $\mathrm{Na}$ tabela 4 estão apresentados dados referentes à vida útil dos materiais, consumo de lanças e o número de lanças utilizadas nos altos-fornos.

Tabela 4. Custos bases envolvidos entre os materiais UNS S30815 e UNS S32109

\begin{tabular}{ccc}
\hline Itens & UNS S30815 & UNS S32109 \\
\hline Número de lanças (10 altos-fornos) & 164 & 164 \\
Vida útil (meses) & 10 & 2 \\
Consumo de lanças em 10 meses & 164 & 820
\end{tabular}


Os custos relacionados à utilização dos dois materiais são apresentados no gráfico 4. Nele, verifica-se que o custo inicial para o UNS S30815 é maior que o do UNS S32109, porém, considerando os custos envolvidos na troca de lanças ao longo de dez meses, observa-se um custo-benefício melhor do material UNS S30815.

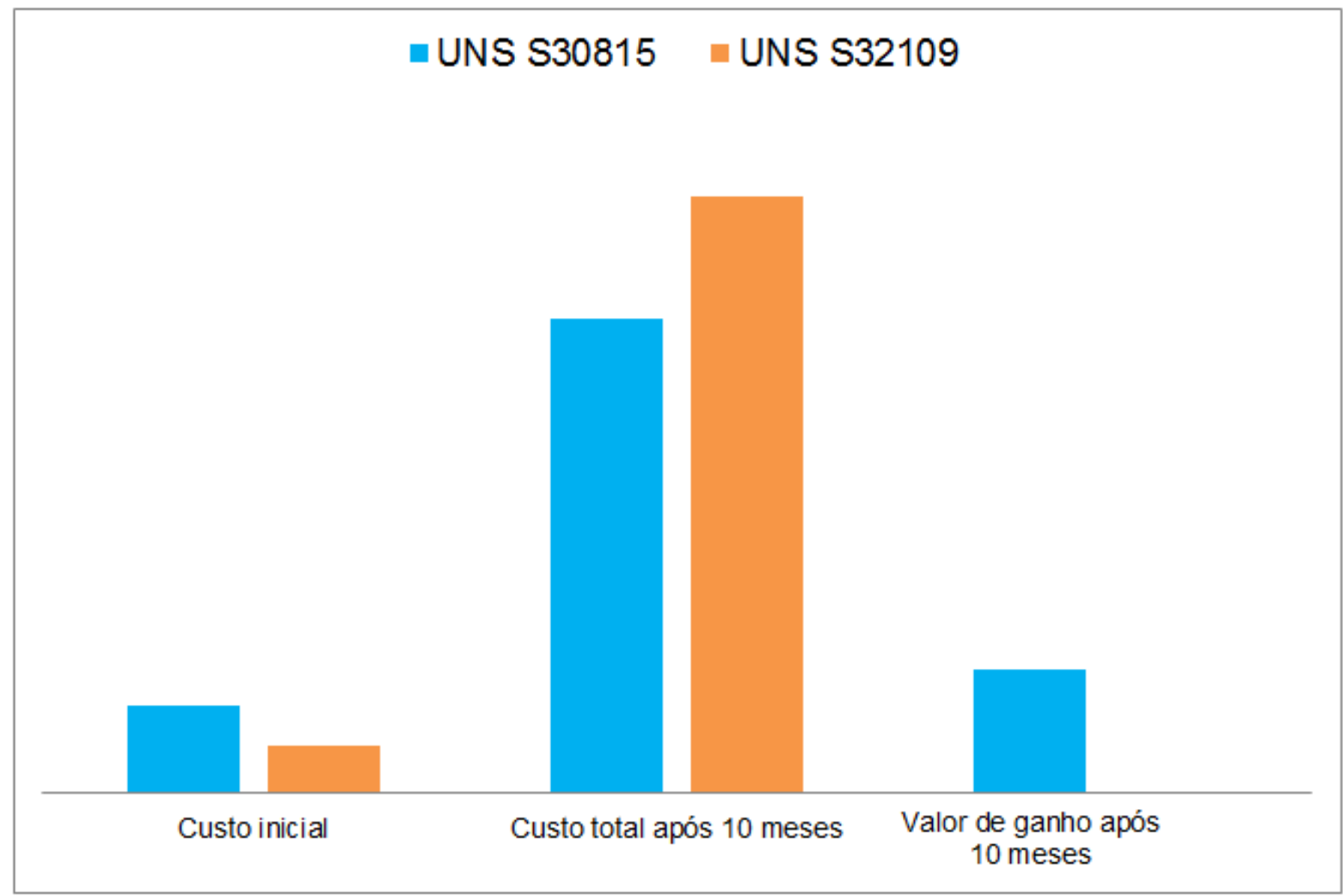

Figura 4. Ganho envolvido na utilização dos materiais UNS S30815.

Ao evitar os custos de reposição de tubos, custos logísticos e mão-de-obra dos operadores, confirma-se que a substituição do material UNS S32109 (TP321H) por Sandvik 253 MA $^{\text {TM }}$ (UNS S30815) traz ganhos ao longo da operação.

\section{CONCLUSÃO}

Considerando as boas propriedades mecânicas, resistência à fluência e à corrosão da liga Sandvik 253 MA $^{\mathrm{TM}}$ (UNS S30815), ela pode ser considerada uma liga de múltipla aplicação. Essa liga é adequada para aplicações onde aços austeníticos que não possuem suficiente resistência à oxidação, carbonetação e fluência falham. Por sua elevada estabilidade estrutural o UNS S30815 pode ser recomendado como substituto a materiais como UNS S32109, UNS S30403 e UNS S31009 que têm maior tendência à formação de fases fragilizantes como, por exemplo, fase sigma. Em razão de a aplicação ser entre as temperaturas críticas de precipitação de fase secundária $\left(800^{\circ} \mathrm{C}\right.$ e $\left.1300^{\circ} \mathrm{C}\right)$ e estar exposto à alta taxa de oxidação, o material UNS S30815 apresenta-se como o mais estável e o mais resistente em função de sua composição química conter Nitrogênio, Silício e metais de terras raras. A resistência à fluência nesta aplicação é primordial, até mesmo para diminuir as chances de ocorrências de incidentes, dado que a lança pode sofrer fluência e injetar carvão diretamente na ventaneira, onde pode furá-la e causar riscos à segurança, pelo fato da água de refrigeração poder cair dentro do alto-forno. 
O estudo de caso na siderúrgica Chinesa mostrou a relevância da seleção correta da liga aplicada nas lanças de injeção de carvão pulverizado (PCl), apresentando ganhos por meio do aumento da vida útil, diminuindo o ciclo de custo como: custos de fabricação e mão-de-obra, perda de produtividade, geração de instabilidade no alto-forno, custo de reposição dos tubos (material), custos logísticos e tempo dos operadores, que precisam com mais frequência trocar as lanças. Portanto, a liga UNS S30815 apresenta-se como uma ótima alternativa para o aumento da vida útil das lanças de injeção de carvão pulverizado.

\section{REFERÊNCIAS}

1 Lai GY. High-Temperature Corrosion and Materials Applications. ASM International. 2007. [acesso em 8 fev. 2016]; 1-445. Disponível em: 10.1361/hcma2007p001

2 Sem referências Bibliográficas. Experiência da empresa.

3 De Oliveira GM, De Oliveira VA, Câdido LS, Assis PS. Estudo do fluxo de materiais pulverizados em simulados de injeção de ventaneiras de altos-fornos através de vídeo-fotografia. 2007. [acesso em 05 abr. 2016]; 1-9. Disponível em: $10.4322 / \mathrm{tmm} .00304002$

4 Datasheet Sandvik 253 MA - Tube and pipe, seamless. 2015.

5 Datasheet Sandvik 353 MA - Tube and pipe, seamless. 2015.

6 Datasheet Sandvik 6R35 - Tube and pipe, seamless. 2015.

7 Datasheet Sandvik 3R12 - Tube and pipe, seamless. 2015.

8 Datasheet Sandvik 7RE10 - Tube and pipe, seamless. 2015.

9 Datasheet Sanicro 31HT - Tube and pipe, seamless. 2015.

10 ASM Specialty Handbook. Heat-Resistant Materials. USA; 1997.

* 253 MA is a trademark owned by Outokumpu Oy. 